\title{
EXPRESSION OF VASCULAR ENDOTHELIAL GROWTH FACTOR (VEGF) IN HEMANGIOMAS AND INTERMEDIATE VASCULAR LESIONS
}

\author{
Ahmed E Zyton ${ }^{1}$ BDS, Hanaa S Raslan² phD, Omneya R Ramadan ${ }^{3} p h D$, Azza Z Abdel \\ $\operatorname{Rahman}^{4} p h D$
}

\begin{abstract} and vascular permeability and promotion of angiogenesis. in diagnosis of each of these tumors Strept-Avidin Biotin method (LSAB). VEGF antibody, with different intensities. KEYWORDS: Vascular tumors, Intermediate vascular tumors, Immunohistochemistry, VEGF.

1. Master student of Oral Pathology, Faculty of Dentistry-Alexandria University

2. Professor of Oral Pathology Department, Faculty of Dentistry-Alexandria University

3. Lecturer of Oral Pathology Department, Faculty of Dentistry-Alexandria University

4. Professor of Oral Medicine Department, Faculty of Dentistry-Alexandria University
\end{abstract}

INTRODUCTION: Vascular tumors of intermediate malignancy encompass a group of tumors whose biologic potential is intermediate between hemangiomas and angiosarcomas. Angiogenesis is characterized by development of new blood vessels through the division or migration of pre-existing vasculature. VEGF deserves attention because it is associated with the stimulation of endothelial cell proliferation

OBJECTIVES: to evaluate the immunohistochemical expression of vascular endothelial growth factor (VEGF) in pyogenic granulomas, hemangiomas and intermediate vascular tumors (hemangioendotheliomas, hemangiopericytomas) and to highlight the possible role of VEGF

MATERIALS AND METHODS: Immunohistochemical analysis of 20 cases of vascular and intermediate vascular tumors, with one section from each specimen (20 sections for VEGF antibody) and 5 control cases. Immunohistochemical staining was performed using a Labeled

RESULTS: Normal gingival tissue showed mild immunoreactivity for VEGF. All the examined cases showed strong positive expression for

CONCLUSIONS: The marker VEGF was overexpressed in vascular and intermediate vascular tumors than normal gingival tissue

\section{INTRODUCTION}

Vascular anomalies are heterogeneous group of congenital lesions of abnormal vascular development and may occur anywhere on the body. There is a primary distinction between a vascular tumor, which grows by cellular hyperplasia, and a vascular malformation, which represents a localized defect in vascular morphogenesis. Due to the differences in biologic behavior and radiographic features, malformations are further subdivided into lowflow and high-flow lesions (1).

Angiogenesis is characterized by the development of new blood vessels through the division or migration of preexisting vasculature. It is observed in a series of physiological and pathological events located in the oral cavity, including inflammation, tissue repair, tumor growth and metastases, in addition to a series of alterations, such as hemangioma and pyogenic granuloma (2).

Pathological angiogenesis is less well controlled and although the initiation and formation stages occur, the vessels rarely mature, remodel or regress in the disease (3). Angiogenesis can be measured by light microscopy through the quantification of blood vessels present in areas of high vessel density in tissues. Blood vessels are detected by the application of antibodies with specific epitopes on endothelial cells, such as von Willebrand factor (vWF) or factor VIII, among others (4).

Vascular Endothelial Growth Factors (VEGFs) are crucial regulators of angiogenesis in the adult. Various angiogenic markers have been identified that can provide diagnostic and prognostic information about these vascular lesions. Among the angiogenic markers used, vascular endothelial growth factor (VEGF) deserves attention because it is associated with the stimulation of endothelial cell proliferation and the promotion of angiogenesis (5). VEGF pathway performed by binding sites identified on vascular endothelial cells corresponding to VEGFR. This distribution on endothelial cells accounts for the selectivity and specificity of action of VEGFR (6).

Various researches examined VEGF expression in certain lesions, as for example in retinoblastomas, it showed positive VEGF expression (7). Also over expression of VEGF has been observed in pulmonary hemangioendotheliomas samples (8). High VEGF expression was observed in $71.4 \%$ of colorectal carcinoma (9). The aim of this study was to evaluate the immunohistochemical expression of vascular endothelial growth factor (VEGF) in pyogenic granulomas, heman mas and intermediate vascular tumors and also to highlight the possible role of VEGF in diagnosis of each of these tumors.

\section{MATERIALS AND METHODS}

The present study was conducted on 20 specimens diagnosed as vascular and intermediate vascular tumors.

One section from each specimen was used. The cases were collected from the Oral Medicine, Faculty of Dentistry, Alexandria University. Five specimens of normal gingiva served as control group, which were biopsied from the gingiva coming from crown lengthening operation. 
A written informed consent was obtained from all the patients. The research protocol was approved by the Ethical Committee of the Faculty of Dentistry.

patients' clinical data were collected from their files, including the patient's age and gender as well as the site of the tumor. The specimens were fixed in $10 \%$ neutral buffered formalin, processed and embedded in paraffin wax using the conventional procedures (10).

Serial sections of $4 \mu \mathrm{m}$ thick were placed on glass slides and stained by (H\&E) for routine histopathological examination. A total of 20 cases were examined, 5 cases were hemangiomas, 4 cases were pyogenic granulomas, 5 cases were hemangioendotheliomas, 6 cases were hemangiopericytomas.

Immunohistochemical staining was performed using a Labeled Strept-Avidin Biotin complex method (LSAB) (11), following manufacturer's kit manual instructions (thermo fisher scientific corporation fremont, CA 94538 USA)

Serial sections of $4 \mu \mathrm{m}$ thick were taken from the same tissue blocks and mounted on poly-L-lysine coated glass slides. The tissue sections were deparaffinized in xylene for 10 minutes, dehydrated in graded series of ethanol and washed twice in phosphate buffered saline (PBS) for 5 minutes. The slide were then left to cool at room temperature for 20 minutes.

To evaluate the VEGF antibody expression, sections were then incubated with the primary antibody VEGF (Abcam, ab1309, UK) for 1 hour at room temperature with 1:50 dilution according to the manufacturer's specifications. After washing in PBS three times for two minutes, sections were incubated in biotinylated secondary antibody in PBS for 30 minutes at room temperature and subsequently with streptavidin-peroxidase conjugate. Then sections were washed in PBS in the same manner. The $0.02 \%$ diaminobenzidinehydrochloride (DAB) containing $0.03 \%$ hydrogen peroxidase used as chromogen to visualize the peroxidase activity. Then they were washed in PBS in the same manner. The tissue sections were washed in water, counterstained by Mayer's hematoxylin (Sigma, USA), and covered with glass slip.

The intensity of immunostaining of VEGF was calculated in terms of optical density and microvessel density by the Computer Image Analyzer System (Leica Microsystems, Swizerland, the software Leica Qwin 500). Microvessel density was determined through counting microvessels in three representative fields with highest density at $\times 400$ magnifications.

\section{Statistical analysis}

Data were fed to the computer and analyzed using IBM SPSS software package version 20.0. Quantitative data were described using range (minimum and maximum), mean, standard deviation and median. Significance of the obtained results was judged at the $5 \%$ level. Mean values were recorded in control and vascular lesions cases and then compared using analysis of variance (ANOVA). Pearson coefficient test was used to correlate between two normally quantitative variables.

\section{RESULTS}

\section{Clinical evaluation}

The present study comprised tissue samples obtained from 20 patients ( 6 males and 14 females), which were diagnosed as vascular and intermediate vascular tumors at Oral
Pathology Department, Faculty of Dentistry, Alexandria University. Base line data of all patients is illustrated in (Table 1).

Table (1): Clinical data of the studied cases according to age, gender and site of the lesion.

\begin{tabular}{|c|c|c|c|c|}
\hline $\begin{array}{c}\text { Number of } \\
\text { cases }\end{array}$ & Diagnosis & Age & Sex & Site \\
\hline 1 & Hemangioma & $2 y$ & Female & Lower lip \\
\hline 2 & Hemangioma & $1.5 \mathrm{y}$ & Female & $\begin{array}{l}\text { Right } \\
\text { eyelid }\end{array}$ \\
\hline 3 & Hemangioma & $40 \mathrm{y}$ & Female & Tongue \\
\hline 4 & Hemangioma & $1,5 \mathrm{y}$ & Female & Forehead \\
\hline 5 & Hemangioma & $1,5 \mathrm{y}$ & Female & Eyelid \\
\hline 6 & Pyogenic granuloma & 35 y & Female & $\begin{array}{l}\text { Buccal } \\
\text { mucosa }\end{array}$ \\
\hline 7 & Pyogenic granuloma & 35 y & Female & $\begin{array}{l}\text { Upper } \\
\text { gingiva }\end{array}$ \\
\hline 8 & Pyogenic granuloma & $32 \mathrm{y}$ & Female & $\begin{array}{l}\text { Lower } \\
\text { gingiva }\end{array}$ \\
\hline 9 & ogenic granuloma & 1 & Male & $\begin{array}{l}\text { Lower } \\
\text { gingiva }\end{array}$ \\
\hline 10 & $\begin{array}{l}\text { Hemangio- } \\
\text { endothelioma }\end{array}$ & $26 y$ & Male & $\begin{array}{l}\text { Anterior } \\
\text { maxilla }\end{array}$ \\
\hline 11 & $\begin{array}{l}\text { Hemangio- } \\
\text { endothelioma }\end{array}$ & $15 \mathrm{y}$ & Male & $\begin{array}{l}\text { Palatal } \\
\text { gingiva }\end{array}$ \\
\hline 12 & $\begin{array}{l}\text { Hemangio- } \\
\text { endothelioma }\end{array}$ & $50 \mathrm{y}$ & Female & palate \\
\hline 13 & $\begin{array}{l}\text { Hemangio- } \\
\text { endothelioma }\end{array}$ & $58 \mathrm{y}$ & Female & $\begin{array}{l}\text { Upper } \\
\text { gingiva }\end{array}$ \\
\hline 14 & $\begin{array}{l}\text { Hemangio- } \\
\text { endothelioma }\end{array}$ & $15 \mathrm{y}$ & Male & Palate \\
\hline 15 & Hemangiopericytoma & $56 y$ & Male & $\begin{array}{l}\text { Buccal } \\
\text { mucosa }\end{array}$ \\
\hline 16 & Hemangiopericytoma & $26 y$ & Female & $\begin{array}{l}\text { Buccal } \\
\text { gingiva }\end{array}$ \\
\hline 17 & Hemangiopericytoma & 81y & Female & Maxilla \\
\hline 18 & Hemangiopericytoma & 32 y & Female & Mandible \\
\hline 19 & Hemangiopericytoma & 33 y & Female & Mandible \\
\hline 20 & Hemangiopericytoma & $57 \mathrm{y}$ & Male & $\begin{array}{l}\text { Buccal } \\
\text { mucosa }\end{array}$ \\
\hline
\end{tabular}

Immunohistochemical results

Normal gingiva showed less immunoreactivity for VEGF antibody than vascular and intermediate vascular tumors. Cases of pyogenic granulomas showed moderate to severe immunopositivity for VEGF antibody. Expression was observed in the cytoplasm of lining endothelial cells (Fig.1). Cases of hemangiomas showed severe immunopositivity for VEGF antibody where expression was detected as evident brownish reaction, cellular reactivity was restricted to the cytoplasm of fibroblasts, as well as in lining of endothelial cells (Fig.2). Cases of hemangioendotheliomas revealed moderate with some cases severe immunopositivity for VEGF antibody (Fig.3). Cases of hemangiopericytomas showed moderate to severe immunopositivity for VEGF antibody with some cases showed different intensities. Expression of VEGF antibody 
has been noted both in pericytes cells as well as in endothelial lining (Fig.4).

In comparing mean optical density between vascular and intermediate vascular tumors using $\mathrm{F}$ test (ANOVA), the difference between hemangioma and hemangioendothelioma was the only one significant, $(\mathrm{p}<0.001)$ (Fig.5).

In comparing mean microvessel density between vascular and intermediate vascular tumors using $F$ test (ANOVA), revealed non significant results $(\mathrm{p}>0.001)$

In comparing mean optical density between vascular anomalies (vascular and intermediate vascular tumors) and normal gingiva using $\mathrm{F}$ test (ANOVA), the difference between them was highly significant

In comparing mean microvessel density between vascular anomalies (vascular and intermediate vascular tumors) and normal gingiva using $F$ test (ANOVA), the difference between them was highly significant.

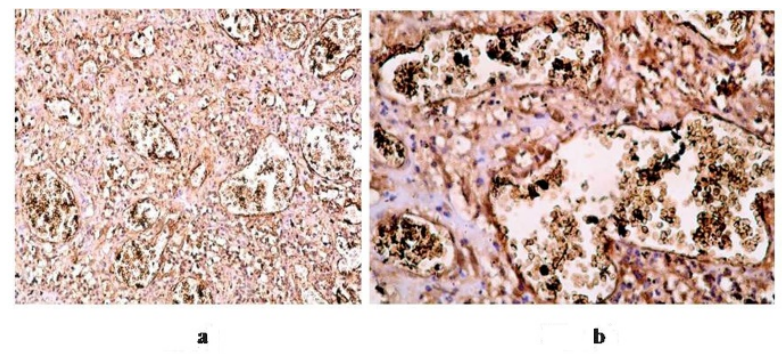

Figure 1: Showing (a) A case of pyogenic granuloma revealing moderate immuno-positivity for VEGF antibody in numerous blood vessels (x200) (b) Higher magnification of pyogenic granuloma revealing moderate immunopositivity for VEGF antibody in the cytoplasm of lining endothelial cells and dilated vascular channels with thick endothelial lining (x400)

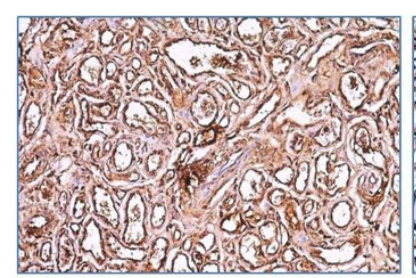

a

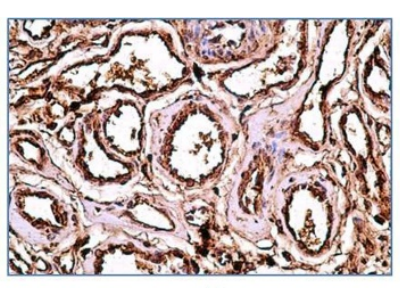

b
Figure 2: (a) A case of hemangioma showing moderate immunopositivity for VEGF antibody with numerous blood vessels (x200) (b) Higher magnification of previous hemangioma showing severe immunopositivity for VEGF antibody restricted to the cytoplasm of fibroblasts, as well as in lining endothelial cells (x400)

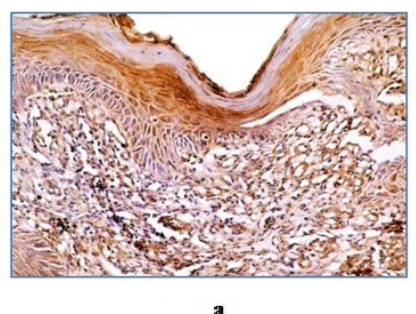

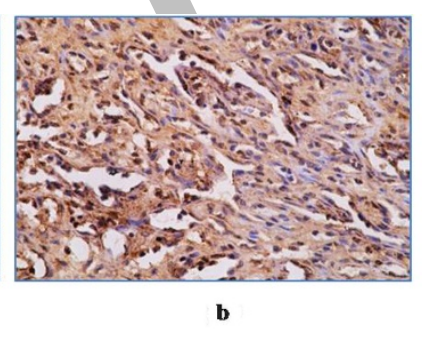

Figure 3: (a) A case of hemangioendothelioma showing moderate immunopositivity with different intensity for VEGF antibody (x200) (b) A case of hemangio-endothelioma showing moderate immunopositivity of endothelial cells lining vascular channels with different intensity for VEGF (x400)
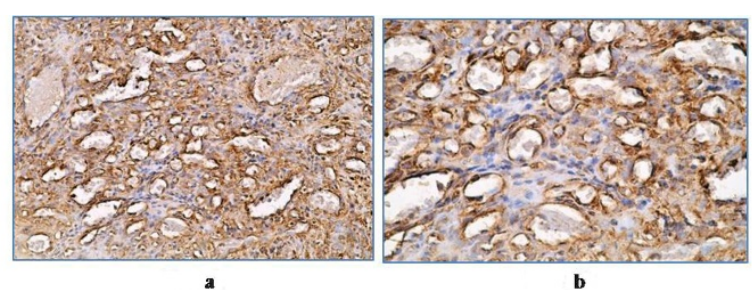

Figure 4: (a) Acase of hemangiopericytomas showing moderate immunopositivity for VEGF antibody (x200) (b) Higher magnification of the previous picture of hemangiopericytoma showing immunopositivity for VEGF in pericytes and endothelium where pericytes are weakely stained than endothelial cells (x400)
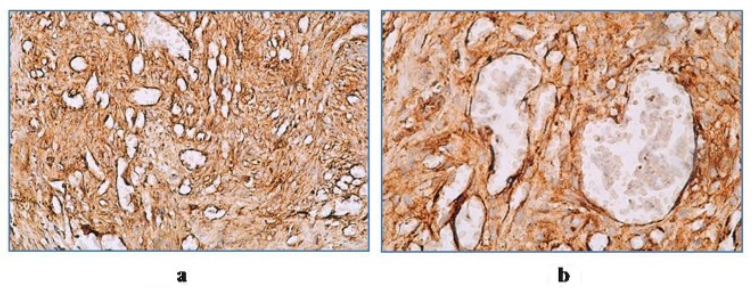

Figure 5: (a) Kposi sarcoma exhibiting immunopositivity of VEGF antibody in endothelial cells with different intensities(x200) (b) Higher magnification of Kaposi sarcoma exhibiting large immature blood vessels, with surrounding endothelial cells showing moderate cytoplasmic immunopositivity of VEGF antibody (x400).

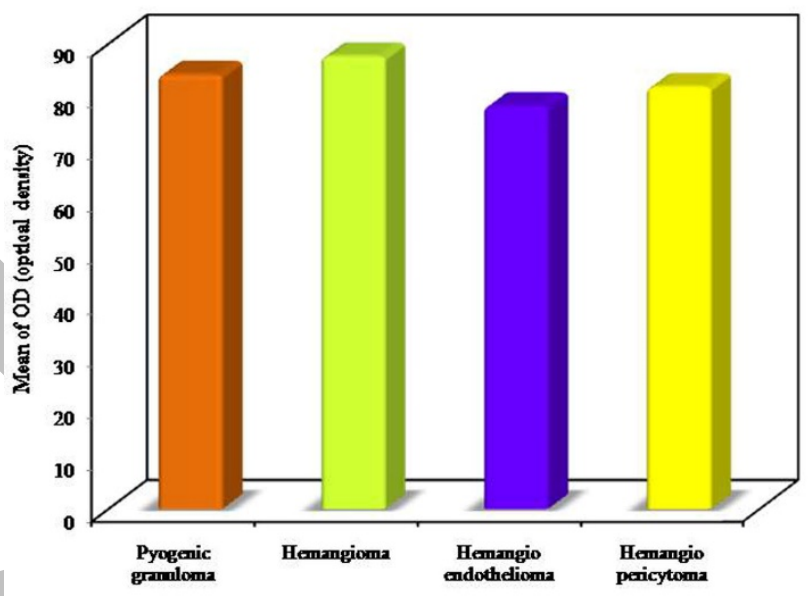

Figure 6: Bar chart showing comparison between different groups according to optical density (OD)

\section{DISCUSSION}

Vascular anomalies are a heterogeneous group of congenital lesions of abnormal vascular development and may occur anywhere on the body. There is a primary distinction between a vascular tumor, which grows by cellular hyperplasia, and a vascular malformation, which represents a localized defect in vascular morphogenesis, due to the differences in biologic behavior and radiographic features. Malformations are further subdivided into low-flow and high-flow lesions (1).

They are histopathologically characterized by a focal increase in the number of vessels that are abnormally tortuous and enlarged. This is likely due to localized defects in vascular development during vasculogenesis and during angiogenesis. The patho-physiological studies of vascular anomalies have been helped by understanding the factors and regulation of the development of the lymphatic and vascular systems (12). 
In studying mean age of patient with pyogenic granulomas, our research showed that they were most prevalent in the third decade of life, which was not in accordance with the research done by Saghafi et al (13), and by Jafarzaddeh et al (14), which demonstrated that pyogenic granuloma was most prevelant in both fourth and second decades of life. In our study, prevalence of pyogenic granuloma was higher in females than males (7:3), which matches with clinical study done by Saghafi et al (13), and this was attributed due to hormonal disturbance related to this period of age.

Mean age of hemangioma in our research was 9.9 years, however this result is in disagreement with studies done by Toida et al (15), where they have reported an older mean age of 52.7 years, in their study to examine immunohistochemical characterization of the vascular elements in lobular capillary hemangioma.

In the present study, mean age of hemangioendothelioma was 36.5 years and this mean age is in accordance with the result studied by Reis-Filho et al (16), where they recorded a mean age of 39.5 years. In our result, mean age of hemangiopericytoma was 47.5 years where this mean is approximating the result obtained by Bhutia and Roychoudhury (17).

In the present work, pyogenic granulomas showed a striking predilection for the gingiva, the interdental papillae being the most common site, so, this result was in accordance with that done by Rizwanulla et al (18). Hemangioma cases included in the present study occurred in tongue, eyelid, forehead and lower lip while previous studies conducted by Zhao-jun et al (19), reported that the most common site was the lip. Most common sites of hemangioendothelioma were the palate and gingiva in our study, however this result was in contrast with that approved by Fukunaga et al (20), who declared that these lesions were more commonly found in the mandibular vestibule. Hemangiopericytoma lesions included in the present research occured mainly at the buccal mucosa and mandible. This result is in contrast with the result reached by Carvalho et al (21), where they found that it is uncommon in the head and neck.

Angiogenesis is a complex process in which there is growth of new blood vessels from the pre-existing ones and is an essential phenomenon for the growth and survival of solid neoplasms. Tumor angiogenesis is the proliferation of blood vessels penetrating the cancerous growth (22). Angiogenesis is needed not only for continued tumor growth, but also for metastasis (23).

In the current study, VEGF antibody expression was investigated in different vascular and intermediate vascular tumors. To our best knowledge, a few studies were conducted on the expression of VEGF antibody in these lesions. According to the The International Society for the Study of Vascular Anomalies (ISSVA), vascular anomalies were histologically divided into several categories (24). The intensity of immunostaining was examined under light microscope. Quantitative evaluations was performed using image analyzer to measure optical density to help to study the possible differences in expression of VEGF antibody in these tumors.

In our research the intensity of staining of cases of normal gingiva with VEGF antibody and its expression were less than of studied tumors, this is in accordance with the study of Yuan et al (25), where they reported that
VEGF antibody was more expressed in pyogenic granuloma than healthy gingiva.

Pyogenic granulomas are benign inflammatory lesions displaying remarkable vascularization. Some of the studied cases of pyogenic granuloma showed intense immunopositivity for VEGF antibody, these results are in accordance with those recorded by Jafarzaddeh et al (14) and Yuan et al (25), although some cases showed moderate immunopositivity to VEGF antibody.

In the present research, all cases of hemangiomas showed intense immunopositivity for VEGF antibody which was detected as an evident brownish reaction. Cellular reactivity was restricted to the cytoplasm of lining endothelial cells and clusters of proliferating endothelial cells without a lumen. These results are in accordance with the study done by JM et al (26), for the expression of VEGF antibody where they found intense positive expression of VEGF antibody, mainly localized in the cytoplasm or cell membrane. our findings were also in accordance with studies done by Miettinen et al (27) and by Zhang et al (28) for vascular endothelial and nonvascular tumors where they found intense positive reaction for the circulating level of vascular endothelial growth factor in hemangiomas.

In the current work, some cases of hemangioendotheliomas showed intense expression of VEGF antibody. These results are in accordance with the research done by Stacher et al (29), in pulmonary hemangioendotheliomas, while the findings are in contrast with the results reported by Miettinen et al (27), where they found a mild expression during immunohistochemical staining.

Some cases of hemangiopericytomas in the present study showed an intense immunopositivity for VEGF antibody. These results are in accordance with the finding of the researches done by those Dietzmann et al (30) and Gengler and Guillou (31), that revealed a severe and diffuse expression in many cases of haemangiopericytomas as well as its receptors in capillary hemangioblastomas, however our results are in contrast with those done by Hatva et al (32) to demonstrate the expression of VEGF antibody in hemangiopericytoma, as it showed a low expression at its cellular membrane.

According to Vermeulen et al (33) the quantification of blood vessels in histological sections can be a useful diagnostic and prognostic indicator in head and neck tumors. However, blood vessel count can be influenced by various factors, including the type of fixative used, pretreatment of the specimens before labeling, the quantification method employed, and the antibody selected.

In comparing between hemangioma and pyogenic granuloma, in this study, hemangioma had a higher optical density than pyogenic granuloma and more intense staining under microscope, however this result are in contrast with the study done by Dyduch et al (34) where they found the VEGF reactivity was higher in pyogenic granuloma compared to hemangioma, and are in contrast with study performed by Yuan et al (25), to compare VEGF antibody expression in oral pyogenic granuloma and hemangioma. This may be due to more intense inflammation and fibrosis of pyogenic granulomas cases.

In this research, In comparing mean microvessel density (MVD) between vascular and intermediate vascular tumors using $\mathrm{F}$ test (ANOVA), it revealed non significant results 
( $\mathrm{p}>0.001$ ), but by comparing mean MVD between vascular and intermediate vascular tumors and normal control cases revealed significant results, so MVD is related to VEGF expression, these finding are in accordance with researches that revealed that MVD is correlated with the level of expression of VEGF antibody by Hasan (35), and in accordance with result of Pakos et al (36), where they record the same results.

However these results are in contrast with the research of Woessner et al (37) in prostatic carcinoma and Tae et al (38) in head and neck tumors, where they demonstrated that MVD is not correlated with the level of expression of VEGF antibody.

\section{CONCLUSION}

This study concludes that VEGF antibody was over expressed by immunohistochemistry in fixed human tissues of vascular and intermediate vascular tumors. VEGF might be an important diagnostic aid in diagnosis of vascular and intermediate vascular tumors. The microvessel denisty is helpful to diagnose vascular proliferation.

\section{CONFLICT OF INTEREST}

The authors declare that they have no conflicts of interest.

\section{REFERENCES}

1. Richter GT, Friedman AB. Hemangiomas and vascular malformations: current theory and management. Int J Pediatr 2012; 2012: 645-78.

2. Sedivy R, Beck-Managetta J, Haverkam PF. Expression of vascular endothelial growth factor-C correlates with the lymphatic microvessel density and the nodal status in oral squamous cell cancer. J Oral Pathol Med 2003; 32: 455-60.

3. Carmeliet P, Jain RK. Angiogenesis in cancer and other diseases. Nature 2000; 407: 249-57.

4. Vermeulen PB, Gasparini G, Foks SB, Colpaert C, Marson LP, Gion M, et al. Second international consensus on the methodology and criteria of evaluation of angiogenesis quantification in solid human tumours. Eur J Cancer 2002; 38: 1564-79

5. Cohen MM Jr. Vasculogenesis, angiogenesis, hemangiomas, and vascular malformations. Am J Med Genet 2002; 108: 265-74.

6. Pajusola K, Aprelikova O, Korhonen J, Kaipainen A, Pertovaara L, Alitalo R, et al. FLT4 receptor tyrosine kinase contains seven immunoglobulin-like loops and is expressed in multiple human tissues and cell lines. Cancer Res 1992; 52: 5738-43

7. Zhou L, Xu J, Kang J. matrix metalloproteinase-9 and vascular endothelial growth factor. Expression of matrix metalloproteinase-2, in retinoblastoma and its clinical significance. Yan Ke Xue Bao 2010; 25: 62-4.

8. Stacher E, Gruber-Mosenbacher U, Halbwedl I, Dei Tos AP, Cavazza A, Papotti M. The VEGF-system in primary pulmonary angiosarcomas and haemangioendotheliomas: new potential therapeutic targets? Lung Cancer 2009; 65: 49-55.

9. Zheng S, Han MY, Xiao ZX, Peng JP, Dong Q. Clinical significance of vascular endothelial growth factor expression and neovascularization in colorectal carcinoma. World J Gastroenterol 2003; 9: 1227-30.
10. Bancroft JD, Stevens A. theory and practice of histological techniques. 3th ed. Churchill livingstone inc. 1990.

11. Grizzle WE. Models of fiation and tissue processing. Biotech Histochem 2009; 84: 185-93

12. Brouillard P, Vikkula M. Vascular malformations: localized defects in vascular morphogenesis. Clin Genet 2003; 63: 340.

13. Saghafi S, Amoueian S, Montazer M, Bostan R. Assessment of VEGF, CD-31 and Ki-67 in Oral Pyogenic Granuloma: A Comparison with Hemangioma and Inflammatory Gingivitis. Iranian J Basic Med Sci 2011; 14: 185-9.

14. Jafarzaddeh H, Sanatkhani M, Mohtasham N. Oral pyogenic granuloma: a review. J Oral Sci 2006; 48: 167-75.

15. Toida M, Hasegawa T, Watanabe F, Kato K, Makita $\mathrm{H}$, Fujitsuka $\mathrm{H}$, et al. Lobular capillary hemangioma of the oral mucosa: clinicopathological study of 43 cases with a special reference to immunohistochemical characterization of the vascular elements. Pathol Int 2003; 53: 1-7.

16. Reis-Filho JS, Paiva ME, Lopes JM. Congenital composite hemangioendothelioma: case report and reappraisal of the hemangioendothelioma spectrum. J Cutan Pathol 2002; 29: 226-31.

17. Bhutia O, Roychoudhury A. Hemangiopericytoma of mandible. J Oral Maxillofac Pathol 2008; 12: 26-8.

18. Rizwanulla T, Koirala B, Shivalal Sharma S, Adhikari L. Klebsiella ozaenae Cholecystitis. Am J Med Sci 2010; 8: 196-8.

19. Zha-jun FU, Chun-ming LI, Wang T, Jiang Z, Zhao-Chen FU. Vascular endothelial growth factor expression and pathological changes in the local tissue of facial hemangiomas following injections with pure alcohol. Oncol Lett 2015; 9: 1099-103.

20. Quante M, Patel NK, Hill S, Merchant W, Courtauld E, Newman P, et al. Epithelioid hemangioendothelioma presenting in the skin: a clinicopathologic study of eight cases. Am J Dermatopathol 1998; 20: 541-6.

21. Carvalho JR, Haddad L, Leonhardt FD, Filho MFM, Santos RO, Cervantes O, et al. Hemangiopericitoma maligno de cabeça e pescoço em uma criança: relato de caso. São Paulo Med J 2004; 122: 223-6.

22. Hasina R, Lingen MW. Angiogenesis and oral cancer. J Dent Educ 2001; 65: 1282-90.

23. Kumar V, Abbas AK, Fausto N. Robbins and Cotran Pathologic basis of disease. 7th ed. Philadelphia; Saunders: Elsevier Inc, 2004. RB111.R62.

24. Hand JL, Frieden IJ. Vascular birthmarks of infancy: Resolving nosologic confusion. Am J Med Genet 2002; 108: 257-264 .

25. Yuan K, Wing TJ, Lin MT. The detection and comparison of angiogenesis-associated factors in pyogenic granuloma by immunohistochemistry. J Periodontol 2000; 71: 701-9.

26. Ou JM, Yu ZY, Qiu MK, Dai YX, Dong Q, Shen J, et al. Knockdown of VEGFR2 inhibits proliferation and induces apoptosis in hemangioma derived endothelial cell. Eur J Histochem 2014; 58: 2263.

27. Miettinen M, Rikala M, Rysz J. VEGF receptor2. As marker for malignant vascular tumors and mesothelioma. Immunohistochemical study of 262 
vascular endothelial and 1640 nonvascular tumors. Am J Surg Pathol 2012: 35: 629-39.

28. Zhang L, Lin X, Wang W, Dong J, Qi Z, Hu Q. Circulating level of vascular endothelial growth factor in differentiating hemangioma from vascular malformation patients. Plast Reconstr Surg 2005; 116: 200-4.

29. Jinnin M, Medici D, Park L, Limaye N, Liu Y, Boscolo E, et al. Uppressed NFAT-dependent VEGFR1 expression and constitutive VEGFR2 signaling in infantile hemangioma. Nat Med 2008; 14: 1236-46.

30. Dietzmann K, von Bossanyi P, Warich-Kirches M, Kirches E. Immuno-histochemical detection of vascular growth factors in angiomatous and atypical meningiomas, as well as hemangiopericytomas. Pathol Res Pract 1997; 193: 503-10.

31. Gengler C, Guillou L. Solitary fibrous tumour and haemangiopericytoma: evolution of a concept. Histopathology 2006; 48: 63-74.

32. Hatva E, Bohling T, Jaaskelainen J, Paetau A, Haltia $\mathrm{M}$, Volk B, et al. Vascular growth factors and receptors in capillary hemangioblastomas and hemangiopericytomas. Am J Pathol 1996; 148: 763-75.

33. Vermeulen PB, Gasparini G, Foks SB, Colpaert C, Marson LP, Gion M, et al. Second international consensus on the methodology and criteria of evaluation of angiogenesis quantification in solid human tumours. Eur J Cancer 2002; 38: 1564-79.

34. Dyduch G, Okoń K, Mierzyński W. Benign vascular proliferations--an immune-histochemical and comparative study. Pol J Pathol 2004; 55: 59-64.

35. Hasan J, Byers R, Jayson GC. Intra-tumoural microvessel density in human solid tumors. Br J Cancer 2002; 86: 1566-77.

36. Pakos EE, Goussia AC, Tsekeris PG, Papachristou DJ, Stefanou D, Agnantis NJ. Expression of vascular endothelial growth factor and its receptor. KDR/Flk-1, in soft tissue sarcomas. Anticancer Res 2005; 25: 35916.

37. Woessner RD, Wright PS, Loudy DE, Wallace CD, Montgomery LR, Nestok BR. Microautoradiographic quantitation of vascular endothelial growth factor mRNA levels in human prostate specimens containing normal and neoplastic epithelium. Exp Mol Pathol 1998; 65: 37-52.

38. Tae K, El-Naggar AK, Yoo E, Feng L, Lee JJ, Hong WK, et al. Expression of vascular endothelial growth factor and microvessel density in head and neck tumorigenesis. Clin Cancer Res 2000; 6: 2821-8. 